\title{
The current and future landscape of dialysis
}

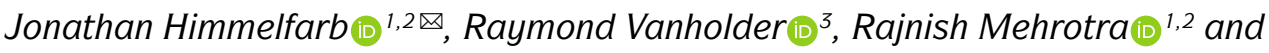 \\ Marcello Tonelli ${ }^{4}$
}

Abstract | The development of dialysis by early pioneers such as Willem Kolff and Belding Scribner set in motion several dramatic changes in the epidemiology, economics and ethical frameworks for the treatment of kidney failure. However, despite a rapid expansion in the provision of dialysis - particularly haemodialysis and most notably in high-income countries (HICs) - the rate of true patient-centred innovation has slowed. Current trends are particularly concerning from a global perspective: current costs are not sustainable, even for $\mathrm{HICs}$, and globally, most people who develop kidney failure forego treatment, resulting in millions of deaths every year. Thus, there is an urgent need to develop new approaches and dialysis modalities that are cost-effective, accessible and offer improved patient outcomes. Nephrology researchers are increasingly engaging with patients to determine their priorities for meaningful outcomes that should be used to measure progress. The overarching message from this engagement is that while patients value longevity, reducing symptom burden and achieving maximal functional and social rehabilitation are prioritized more highly. In response, patients, payors, regulators and health-care systems are increasingly demanding improved value, which can only come about through true patient-centred innovation that supports high-quality, high-value care. Substantial efforts are now underway to support requisite transformative changes. These efforts need to be catalysed, promoted and fostered through international collaboration and harmonization.

${ }^{1}$ Kidney Research Institute, Seattle, WA, USA

${ }^{2}$ Division of Nephrology, Department of Medicine, University of Washington, Seattle, WA, USA.

${ }^{3}$ Nephrology Section, Department of Internal Medicine and Pediatrics, University Hospital, Ghent, Belgium and European Kidney Health Alliance (EKHA), Brussels, Belgium.

${ }^{4}$ Division of Nephrology, Department of Medicine, University of Calgary, Calgary, Alberta, Canada 凶e-mail: Jhimmelfarb@ Nephrology.washington.edu https://doi.org/10.1038/ s41581-020-0315-4
Haemodialysis as a treatment for irreversible kidney failure arose from the pioneering efforts of Willem Kolff and Belding Scribner, who together received the 2002 Albert Lasker Clinical Medical Research Award for this accomplishment. Kolff treated his first patient with an artificial kidney in 1943 - a young woman who was dialysed 12 times successfully but ultimately died because of vascular access failure. By 1945, Kolff had dialysed 15 more patients who did not survive, when Sofia Schafstadt - a 67-year-old woman who had developed acute kidney injury - recovered, becoming the first long-term survivor after receipt of dialysis. In 1960, Belding Scribner, Wayne Quinton and colleagues at the University of Washington, WA, USA, designed shunted cannulas, which prevented the destruction of blood vessels and enabled repeated haemodialysis sessions. The first patient who received long-term treatment (named Clyde Shields) lived a further 11 years on haemodialysis. In their writings, both Kolff and Scribner eloquently described being motivated by their perception of helplessness as physicians who had little to offer for the care of young patients who were dying of uraemia and stated that the goal of dialysis was to achieve full rehabilitation to an enjoyable life ${ }^{1}$.
The potential to scale the use of dialysis to treat large numbers of patients with kidney failure created great excitement. At the 1960 meeting of the American Society for Artificial Internal Organs (ASAIO), Scribner introduced Clyde Shields to physicians interested in dialysis, and Quinton demonstrated fabrication of the shunt. The following decade saw rapid gains in our understanding of kidney failure, including the discovery of uraemia-associated atherogenesis and metabolic bone disease, and in virtually every aspect of haemodialysis, including improvements in dialyser technology, dialysate composition, materials for haemocompatibility and water purification systems. The Scribner-Quinton shunt rapidly became an historical artefact once Brescia and colleagues developed the endogenous arteriovenous fistula in 1966 (REF. ${ }^{2}$ ), and prosthetic subcutaneous interpositional 'bridge' grafts were developed shortly thereafter. Concomitant with these pioneering efforts, in 1959, peritoneal dialysis (PD) was first used successfully to sustain life for 6 months. Within 2 years a long-term PD programme was established in Seattle, WA, USA, and within 3 years the first automated PD cycler was developed ${ }^{3}$.

In 1964, Scribner's presidential address to the ASAIO described emerging ethical issues related to dialysis, 


\section{Key points}

- The global dialysis population is growing rapidly, especially in low-income and middle-income countries; however, worldwide, a substantial number of people lack access to kidney replacement therapy, and millions of people die of kidney failure each year, often without supportive care.

- The costs of dialysis care are high and will likely continue to rise as a result of increased life expectancy and improved therapies for causes of kidney failure such as diabetes mellitus and cardiovascular disease.

- Patients on dialysis continue to bear a high burden of disease, shortened life expectancy and report a high symptom burden and a low health-related quality of life.

- Patient-focused research has identified fatigue, insomnia, cramps, depression, anxiety and frustration as key symptoms contributing to unsatisfactory outcomes for patients on dialysis.

- Initiatives to transform dialysis outcomes for patients require both top-down efforts (that is, efforts that promote incentives based on systems level policy, regulations, macroeconomic and organizational changes) and bottom-up efforts (that is, patient-led and patient-centred advocacy efforts as well as efforts led by individual teams of innovators).

- Patients, payors, regulators and health-care systems increasingly demand improved value in dialysis care, which can only come about through true patient-centred innovation that supports high-quality, high-value care.

including considerations for patient selection, patient self-termination of treatment as a form of suicide, approaches to ensure death with dignity and selection criteria for transplantation ${ }^{4}$. Indeed, the process of selecting who would receive dialysis contributed to the emergence of the field of bioethics. The early success of dialysis paradoxically created social tensions, as access to this life-sustaining therapy was rationed by its availability and the 'suitability' of patients. In the early 1970s, haemodialysis remained a highly specialized therapy, available to $\sim 10,000$ individuals, almost exclusively in North America and Europe, with a high frequency of patients on home haemodialysis. In a portentous moment, Shep Glazer, an unemployed salesman, was dialysed in a live demonstration in front of the US Congress House Ways and Means Committee. Soon thereafter, in October 1972, an amendment to the Social Security Act creating Medicare entitlement for end-stage renal disease (now known as kidney failure), for both dialysis and kidney transplantation, was passed by Congress and signed into law by President Nixon.

The resulting expansion of dialysis, previously described as "from miracle to mainstream", set in motion dramatic changes ${ }^{6}$, including the development of a for-profit outpatient dialysis provider industry; relaxation of stringent patient selection for dialysis eligibility in most HICs; a move away from home towards in-centre dialysis; efforts on the part of single payors such as Medicare in the USA to restrain per-patient costs through the introduction of bundled payments and the setting of composite rates; the development of quality indicators - such as adequate urea clearance per treatment - that were readily achievable but are primarily process rather than outcome measures; consolidation of the dialysis industry, particularly in the USA owing to economies of scale, eventually resulting in a duopoly of dialysis providers; the development of joint ventures and other forms of partnerships between dialysis providers and nephrologists; the globalization of dialysis, which is now available, albeit not necessarily accessible or affordable in many low-income and middle-income countries (LMICs); and finally, a dramatic slowing in the rate of true patient-centred innovation, with incremental gains in dialysis safety and efficiency replacing the pioneering spirit of the early innovators.

The population of patients receiving dialysis continues to grow rapidly, especially in LMICs, as a result of an increase in the availability of dialysis, population ageing, increased prevalence of hypertension and diabetes mellitus, and toxic environmental exposures. However, despite the global expansion of dialysis, notable regional differences exist in the prevalence of different dialysis modalities and in its accessibility. Worldwide, a substantial number of people do not have access to kidney replacement therapy (KRT), resulting in millions of deaths from kidney failure each year. Among populations with access to dialysis, mortality remains high and outcomes suboptimal, with high rates of comorbidities and poor health-related quality of life. These shortcomings highlight the urgent need for innovations in the dialysis space to increase accessibility and improve outcomes, with a focus on those that are a priority to patients. This Review describes the current landscape of dialysis therapy from an epidemiological, economic, ethical and patient-centred framework, and provides examples of initiatives that are aimed at stimulating innovations in dialysis and transform the field to one that supports high-quality, high-value care.

\section{Epidemiology of dialysis}

Kidney failure is defined by a glomerular filtration rate $<15 \mathrm{ml} / \mathrm{min} / 1.73 \mathrm{~m}^{2}$ (REF. ${ }^{7}$ ) and may be treated using KRT (which refers to either dialysis or transplantation) or with supportive care ${ }^{8}$. The global prevalence of kidney failure is uncertain, but was estimated to be $0.07 \%$, or approximately 5.3 million people in 2017 (REF. ${ }^{9}$ ), with other estimates ranging as high as 9.7 million. Worldwide, millions of people die of kidney failure each year owing to a lack of access to KRT ${ }^{10}$, often without supportive care. Haemodialysis is costly, and current recommendations therefore suggest that haemodialysis should be the lowest priority for LMICs seeking to establish kidney care programmes. Rather, these programmes should prioritize other approaches, including treatments to prevent or delay kidney failure, conservative care, living donor kidney transplantation and $\mathrm{PD}^{11}$. Nonetheless, haemodialysis is the most commonly offered form of KRT in LMICs, as well as in high-income countries (HICs) ${ }^{12}$, and continued increases in the uptake of haemodialysis are expected worldwide in the coming decades. Here, we review the basic epidemiology of kidney failure treated with long-term dialysis and discuss some of the key epidemiological challenges of the future (FIG. 1a).

\section{Prevalence of dialysis use}

Prevalence of haemodialysis. Worldwide, approximately $89 \%$ of patients on dialysis receive haemodialysis; the majority ( $>90 \%$ ) of patients on haemodialysis live in HICs or the so-called upper middle-income countries such as Brazil and South Africa ${ }^{12,13}$. The apparent prevalence of long-term dialysis varies widely by region but 

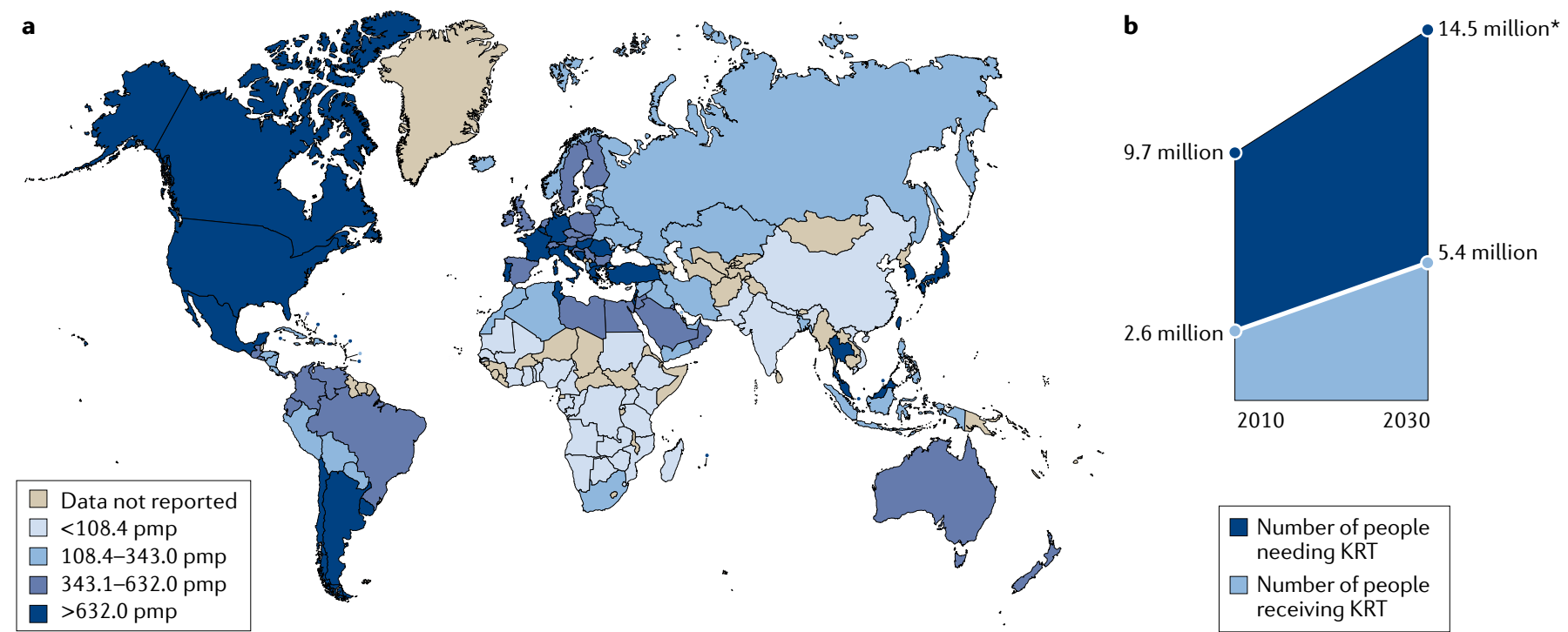

Fig. 1 | Current and projected prevalence of kidney failure requiring kidney replacement therapy. Growth is continuously outpacing the capacity of kidney replacement therapy (KRT), defined as maintenance dialysis or kidney transplant, especially in low-income and middle-income countries. a | Global prevalence of chronic dialysis. $\mathbf{b}$ | Estimated worldwide need and projected capacity for KRT by 2030. pmp, per million population. Adapted with permission from the ISN Global Kidney Health Atlas 2019.

correlates strongly with national income ${ }^{14}$. This variation in prevalence in part reflects true differences in dialysis use ${ }^{12,15}$ but also reflects the fact that wealthier countries are more likely than lower income countries to have comprehensive dialysis registries. Of note, the prevalence of haemodialysis is increasing more rapidly in Latin America (at a rate of $\sim 4 \%$ per year) than in Europe or the USA (both $\sim 2 \%$ per year), although considerable variation between territories exists in all three of these regions, which again correlates primarily (but not exclusively) with wealth ${ }^{16,17}$. The prevalence of haemodialysis varies widely across South Asia, with relatively high prevalence (and rapid growth) in India and lower prevalence in Afghanistan and Bangladesh ${ }^{18}$. Limited data are available on the prevalence of dialysis therapies in sub-Saharan Africa $^{19}$. A 2017 report suggests that haemodialysis services were available in at least 34 African countries as of 2017, although haemodialysis was not affordable or accessible to the large majority of resident candidates ${ }^{13}$.

Prevalence of peritoneal dialysis. Worldwide, PD is less widely available than haemodialysis. In a 2017 survey of 125 countries, PD was reportedly available in $75 \%$ of countries whereas haemodialysis was available in $96 \%{ }^{20}$. In 2018 , an estimated $11 \%$ of patients receiving longterm dialysis worldwide were treated with $\mathrm{PD}$; a little over half of these patients were living in China, Mexico, the USA and Thailand ${ }^{21}$.

Large variation exists between territories in the relative use of PD for treating kidney failure; in Hong Kong for example, $>80 \%$ of patients on dialysis receive $\mathrm{PD}$, whereas in Japan this proportion is $<5 \%{ }^{22}$. This variation is, in part, determined by governmental policies and the density of haemodialysis facilities ${ }^{23}$. In some countries such as the USA, rates of PD utilization also vary by ethnicity with African Americans and Hispanics being much less likely than white Americans to receive $\mathrm{PD}^{24}$. Disparate secular trends in PD use are also evident, with rapid growth in the use of $\mathrm{PD}$ in some regions such as the USA, China and Thailand and declining or unchanging levels of PD use in other regions, for example, within Western Europe ${ }^{22}$. As for haemodialysis, access to PD is poor in many LMICs for a variety of reasons, as comprehensively discussed elsewhere ${ }^{25}$.

\section{Incidence of dialysis use}

Following a rapid increase in dialysis use over a period of approximately two decades, the incidence of dialysis initiation in most HICs reached a peak in the early 2000s and has remained stable or slightly decreased since then $^{22,26,27}$. Extrapolation of prevalence data from LMICs suggests that the incidence of dialysis initiation seems to be steadily increasing in $\mathrm{LMICs}^{10,28-30}$, with further increases expected over the coming decades. However, incidence data in LMICs are less robust than prevalence data, although neither reflect the true demand for KRT given the lack of reporting.

Of note, the incidence of dialysis initiation in HICs is consistently 1.2-fold to 1.4-fold higher for men than for women, despite an apparently higher risk of chronic kidney disease (CKD) in women ${ }^{31}$. Whether this finding reflects physician or health system bias, different preferences with regard to KRT, disparities in the competing risk of death, variation in rates of kidney function loss in women versus men, or other reasons is unknown and requires further study. Few data describe the incidence of haemodialysis by sex in LMICs.

\section{Dialysis outcomes}

Mortality. Mortality is very high among patients on dialysis, especially in the first 3 months following initiation of haemodialysis treatment. Approximately one-quarter 
of patients on haemodialysis die within a year of initiating therapy in HICs, and this proportion is even higher in $\mathrm{LMICs}^{32-34}$. Over the past two decades, reductions in the relative and absolute risk of mortality have seemingly been achieved for patients on haemodialysis. Data suggest that relative gains in survival may be greater for younger than for older individuals; however, absolute gains seem to be similar across age groups ${ }^{35}$. Although controversial, improvements in mortality risk seem to have been more rapid among patients on dialysis than for the general population ${ }^{36}$, suggesting that better care of patients receiving dialysis treatments rather than overall health gains might be at least partially responsible for these secular trends. The factors responsible for these apparent trends have not been confirmed, but could include better management of comorbidities, improvements in the prevention or treatment of dialysis-related complications such as infection, and/or better care prior to the initiation of dialysis (which may translate into better health following dialysis initiation). Historically, although short-term mortality was lower for patients treated with PD than for those treated with haemodialysis, the long-term mortality risk was higher with $\mathrm{PD}^{37,38}$. In the past two decades, the reduction in mortality risk has been greater for patients treated with PD than with haemodialysis, such that in most regions the long-term survival of patients treated with PD and haemodialysis are now similar ${ }^{39-41}$.

Despite these improvements, mortality remains unacceptably high among patients on dialysis and is driven by cardiovascular events and infection. For example, a 2019 study showed that cardiovascular mortality among young adults aged 22-29 years with incident kidney failure was 143-500-fold higher than that of otherwise comparable individuals without kidney failure, owing to a very high burden of cardiovascular risk factors ${ }^{42}$. The risk of infection is also markedly greater among patients on dialysis than in the general population, in part driven by access-related infections in patients on haemodialysis with central venous catheters and peritonitis-related infections in patients on $\mathrm{PD}^{43-47}$. Hence, strategies to reduce the risk of infection associated with dialysis access should continue to be a high clinical priority.

The risk of mortality among patients on dialysis seems to be influenced by race. In the USA, adjusted mortality is lower for African American patients than for white patients on dialysis, although there is a significant interaction with age such that this observation held only among older adults, and the converse is actually true among younger African American patients aged 18 to 30 years $^{48}$. A similar survival advantage is observed among Black patients compared with white patients or patients of Asian heritage on haemodialysis in the Netherlands ${ }^{49}$. In Canada, dialysis patients of indigenous descent have higher adjusted mortality, and patients of South Asian or East Asian ethnicity have lower adjusted mortality than that of white patients. In addition, between-region comparisons indicate that mortality among incident dialysis patients is substantially lower for Japan than for other HICs. Whether this difference is due to ethnic origin, differences in health system practices, a combination of these factors or other, unrelated factors is unknown $^{30}$. No consistent evidence exists to suggest that mortality among incident adult dialysis patients varies significantly by $\operatorname{sex}^{50-52}$.

Other outcomes. Hospitalization, inability to work and loss of independent living are all markedly more common among patients on dialysis than in the general population ${ }^{53-55}$. In contrast to the modest secular improvements in mortality achieved for patients on dialysis, health-related quality of life has remained unchanged for the past two decades and is substantially lower than that of the general population, due in part to high symptom burden ${ }^{56-59}$. Depression is also frequent among patients on dialysis ${ }^{60}$, and factors such as high pill burden ${ }^{61}$, the need to travel to dialysis sessions and pain associated with vascular access puncture all affect quality of life ${ }^{62}$.

\section{Future epidemiological challenges}

The changing epidemiology of kidney failure is likely to present several challenges for the optimal management of these patients. For example, the ageing global population together with continuing increases in the prevalence of key risk factors for the development of kidney disease, such as diabetes mellitus and hypertension, mean that the incidence, prevalence and costs of kidney failure will continue to rise for the foreseeable future. This increased demand for KRT will undoubtedly lead to an increase in the uptake of haemodialysis, which will pose substantial economic challenges for health systems worldwide. Moreover, as growth in demand seems to be outpacing increases in KRT capacity, the number of deaths as a result of kidney failure is expected to rise dramatically (FIG. 1 b).

The same risk factors that drive the development of kidney disease will also increase the prevalence of multimorbidities within the dialysis population. These comorbidities will in turn require effective management in addition to the management of kidney failure per $\mathrm{se}^{63}$ and will require technical innovations of dialysis procedures, as well as better evidence to guide the management of comorbidities in the dialysis population.

Finally, the particularly rapid increases in the incidence and prevalence of kidney failure among populations in LMICs will place considerable strain on the health systems of these countries. The associated increases in mortality resulting from a lack of access to KRT will create difficult choices for decision makers. Although LMIC should prioritize forms of KRT other than haemodialysis, some haemodialysis capacity will be required ${ }^{11}$, for example, to manage patients with hypercatabolic acute kidney injury or refractory PD-associated peritonitis, which, once available, will inevitably increase the use of this modality.

\section{Health economy-related considerations}

The cost of dialysis (especially in-centre or in-hospital dialysis) is high ${ }^{64}$, and the cost per quality-adjusted life-year associated with haemodialysis treatment is often considered to be the threshold value that differentiates whether a particular medical intervention is cost-effective or not ${ }^{65}$. Total dialysis costs across the population will 


\section{Box 1 Main ethical issues in dialysis}

\section{Equity in access to long-term dialysis}

- Inequities in the ability to access kidney replacement therapy exist worldwide; however, if dialysis is available, the ability to transition between different dialysis modalities should be facilitated as much as possible. Specific attention should be paid to the factors that most prominently influence access to dialysis, such as gender, ethnicity, citizenship status and socio-economic status

\section{Impact of financial interests on dialysis delivery}

- Financial interests of dialysis providers or nephrologists should in no way influence the choice of dialysis modality and/or result in the non-referral of patients for transplantation or conservative care

\section{Cost considerations}

- Local adaptations are needed to ensure that the costs of dialysis provision are as low as possible without compromising quality of care

- The high cost of dialysis means that consideration must be given to whether the benefits obtained by dialysis outweigh those obtained by addressing other health-care priorities, such as malaria or tuberculosis

\section{Shared decision-making}

- Shared decision-making, involving the patient and their family, is recommended as an approach to allow an informed choice of the most appropriate course to follow

- Approaches to shared decision-making must be evidence based and adapted to local circumstances

- Futile dialysis should be avoided

- Proper training is required to prepare physicians for shared decision-making

\section{Societal costs}

The share of treatment cost paid by society; that is, by government or insurers.

Reimbursement

Money paid by governments or insurers to health-care

providers for money spent on treatment.

Economic strength The value of everything produced in that country at the prices prevailing in that country, usually expressed as gross domestic product.

Willingness to pay

The maximum price at or below which a society is

prepared to buy a product.

Gross domestic product The monetary value of all finished goods and services made within a country during a specific period.

Global health budget

Total amount of money spent by government on health care. probably continue to rise, owing to increases in life expectancy of the general population and the availability of improved therapeutics for causes of kidney failure such as diabetes mellitus, which have increased the lifespan of these patients and probably will also increase their lifespan on dialysis. KRT absorbs up to $5-7 \%$ of total health-care budgets, despite the fact that kidney failure affects only $0.1-0.2 \%$ of the general population in most regions ${ }^{66}$. Although societal costs for out-of-centre dialysis (for example, home or self-care haemodialysis, or PD) are in general lower than that of in-centre haemodialysis in many HICs, these options are often underutilized $^{67}$, adding to the rising costs of dialysis.

Reimbursement for haemodialysis correlates with the economic strength of each region ${ }^{68}$, but in part also reflects willingness to pay. In most regions, the correlation curve for PD or reimbursement with respect to gross domestic product projects below that of in-centre haemodialysis, which in part reflects the lower labour costs associated with $\mathrm{PD}^{68}$. Unfortunately, little clarity exists with regard to the aggregated cost of single items that are required to produce dialysis equipment for both PD and haemodialysis and the labour costs involved in delivering haemodialysis ${ }^{69}$, which makes it difficult for governments to reimburse the real costs of haemodialysis.

Although increasing reimbursement of home dialysis strategies would seem to be an appropriate strategy to stimulate uptake of these modalities, evidence from regions that offer high reimbursement rates for $\mathrm{PD}$ suggests that the success of this strategy is variable ${ }^{23,68}$. However, financial incentives may work. In the USA, reimbursement for in-centre and home dialysis (PD or home haemodialysis) has for a long time been identical. The introduction of the expanded prospective payment system in 2011 further enhanced the financial incentives for PD for dialysis providers, which led to a doubling in both the absolute number of patients and the proportion of patients with kidney failure treated with $\mathrm{PD}^{70-73}$.

Although in countries with a low gross domestic product, dialysis consumes less in absolute amounts, it absorbs a higher fraction of the global health budget ${ }^{68}$, likely at the expense of other, potentially more cost-effective interventions, such as prevention or transplantation. Although society carries most of the costs associated with KRT in most HICs, some costs such as co-payment for drugs or consultations are borne by the individual, and these often increase as CKD progresses. In other regions, costs are covered largely or entirely by the patient's family, leading to premature death when resources are exhausted ${ }^{74}$. In addition, costs are not limited to KRT but also include the costs of medication, hospitalizations and interventions linked to kidney disease or its complications (that is, indirect costs), as well as non-health-care-related costs such as those linked to transportation or loss of productivity.

Dialysis also has an intrinsic economic impact. Patients on dialysis are often unemployed. In the USA, $>75 \%$ of patients are unemployed at the start of dialysis, compared with $<20 \%$ in the general population ${ }^{53}$. Unemployment affects purchasing power but also lifestyle, self-image and mental health. Moreover, loss of productivity owing to unemployment and/or the premature death of workers with kidney failure also has economic consequences for society ${ }^{75}$. Therefore, continued efforts to prevent kidney failure and develop KRT strategies that are less time consuming for the patient and allow more flexibility should be an urgent priority. Concomitantly, employers must also provide the resources needed to support employees with kidney failure.

Hence, a pressing need exists to rethink the current economic model of dialysis and the policies that direct the choice of different treatment options. The cost of dialysis (especially that of in-centre haemodialysis) is considerable and will continue to rise as the dialysis population increases. Maintaining the status quo will prevent timely access to optimal treatment for many patients, especially for those living in extreme poverty and with a low level of education and for patients living in LMICs.

\section{Ethical aspects}

A 2020 review by a panel of nephrologists and ethicists appointed by three large nephrology societies outlined the main ethical concerns associated with kidney care ${ }^{76}$. With regard to management of kidney failure (BOX 1), equitable access to appropriate treatment is probably the most important ethical issue and is relevant not only in the context of haemodialysis but also for the other modalities of kidney care (including transplantation, $\mathrm{PD}$ and comprehensive conservative care $)^{76}$. Of note, conservative care is not equivalent to the withdrawal of treatment, but rather implies active management excluding KRT.

As mentioned previously, access to such care is limited in many countries ${ }^{10,77}$. Inequities in access to dialysis at the individual level are largely dependent on factors such as health literacy, education and socio-economic 
status, but also on the wealth and organization of the region in which the individual lives. Even when dialysis itself is reimbursed, a lack of individual financial resources can limit access to care. Moreover, elements such as gender, race or ethnicity and citizenship status ${ }^{78,79}$ can influence an individual's ability to access dialysis ${ }^{80}$. These factors impose a risk that patients who are most vulnerable are subject to further discrimination. In addition, without necessarily being perceived as such, dialysis delivery may be biased by the financial interests of dialysis providers or nephrologists, for example, by influencing whether a patient receives in-centre versus home dialysis, or resulting in the non-referral of patients on dialysis for transplantation or conservative care ${ }^{81,82}$.

A potential reason for the high utilization of in-centre haemodialysis worldwide is a lack of patient awareness regarding the alternatives. When surveyed, a considerable proportion of patients with kidney failure reported that information about options for KRT was inadequate ${ }^{83,84}$. Patient education and decision support could be strengthened and its quality benchmarked, with specific attention to low health literacy, which is frequent among patients on dialysis ${ }^{85}$. Inadequate patient education might result from a lack of familiarity with home dialysis (including PD) and candidacy bias among treating physicians and nurses. Appropriate education and training of medical professionals could help to solve this problem. However, the first step to increase uptake of home dialysis modalities is likely policy action undertaken by administrations, but stimulated by advocacy by patients and the nephrology community, as suggested by the higher prevalence of PD at a lower societal cost of regions that already have a PD-first policy in place ${ }^{68}$.

Although the provision of appropriate dialysis at the lowest possible cost to the individual is essential if access is to be improved ${ }^{86}$, approaches that unduly compromise the quality of care should be minimized or avoided. General frameworks to deal with this challenge can be provided by the nephrology community, but trade-offs between cost and quality may be necessary and will require consultation between authorities, medical professionals and patient representatives. Consideration must also be given to whether the societal and individual impact of providing dialysis would be greater than managing other societal health priorities (for example, malaria or tuberculosis) or investing in other sectors to improve health (for example, access to clean drinking water or improving road safety).

The most favourable approach in deciding the most appropriate course of action for an individual is shared decision-making ${ }^{87}$, which provides evidence-based information to patients and families about all available therapeutic options in the context of the local situation. Providing accurate and unbiased information to support such decision-making is especially relevant for conservative care, to avoid the perception that this approach is being recommended to save resources rather than to pursue optimal patient comfort. Properly done, shared decision-making should avoid coercion, manipulation, conflicts of interest and the provision of 'futile dialysis' to a patient for whom the harm outweighs the benefits, life expectancy is low or the financial burden is high ${ }^{88}$.
However, the views of care providers do not always necessarily align with those of patients and their families, especially in multicultural environments ${ }^{89}$. Medical professionals are often not well prepared for shared decision-making, and thus proper training is essential ${ }^{90}$. Policy action is also required to create the proper ethical consensus and evidence-based frameworks at institutional and government levels ${ }^{91}$ to guide decision-making in the context of dialysis care that can be adapted to meet local needs.

\section{Clinical outcomes to measure progress}

Over the past six decades, the availability of long-term dialysis has prolonged the lives of millions of people worldwide, often by serving as a bridge to kidney transplantation. Yet, patients on dialysis continue to bear a high burden of disease, both from multimorbidity and owing to the fact that current dialysis modalities only partially replace the function of the native kidney, resulting in continued uraemia and its consequences. Thus, although dialysis prevents death from kidney failure, life expectancy is often poor, hospitalizations (particularly for cardiovascular events and infection) are frequent, symptom burden is high and health-related quality of

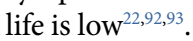

Given the multitude of health challenges faced by patients on dialysis, it is necessary to develop a priority list of issues. For much of the past three decades, most of this prioritization was performed by nephrology researchers with the most effort to date focusing on approaches to reducing all-cause mortality and the risk of fatal and non-fatal cardiovascular events. However, despite the many interventions that have been tested, including increasing the dose of dialysis (in the HEMO and ADEMEX trials ${ }^{94,95}$ ), increasing dialyser flux (in the HEMO trial and MPO trial ${ }^{94,96}$ ), increasing haemodialysis frequency (for example, the FHN Daily and FHN Nocturnal trials ${ }^{97,98}$ ), use of haemodiafiltration (the CONTRAST ${ }^{99}$, ESHOL $^{100}$ and TURKISH-OL-HDF trials ${ }^{101}$ ), increasing the haemoglobin target (for example, the Normal Haematocrit Trial ${ }^{102}$ ), use of non-calcium-based phosphate binders (for example, the DCOR trial ${ }^{103}$ ), or lowering of the serum cholesterol level (for example, the 4D, AURORA and SHARP trials $\left.{ }^{104-106}\right)$, none of these or other interventions has clearly reduced all-cause or cardiovascular mortality for patients on dialysis. These disappointments notwithstanding, it is important that the nephrology community perseveres in finding ways to improve patient outcomes.

In the past 5 years, nephrology researchers have increasingly engaged with patients to understand their priorities for meaningful outcomes that should be used to measure progress. The overarching message from this engagement is that although longevity is valued, many patients would prefer to reduce symptom burden and achieve maximal functional and social rehabilitation. This insight highlights the high symptom burden experienced by patients receiving long-term dialysis ${ }^{92,93,96,107}$. These symptoms arise as a consequence of the uraemic syndrome. Some of these symptoms, such as anorexia, nausea, vomiting, shortness of breath and confusion or encephalopathy, improve with dialysis initiation ${ }^{108-110}$, 
but many other symptoms, such as depression, anxiety and insomnia do not. Moreover, other symptoms, such as post-dialysis fatigue, appear after initiation of haemodialysis.

Of note, many symptoms of uraemic syndrome might relate to the persistence of protein-bound uraemic toxins and small peptides (so-called middle molecules) that are not effectively removed by the current dialysis modalities. The development of methods to improve the removal of those compounds is one promising approach to improving outcomes and quality of life for patients on dialysis, as discussed by other articles in this issue.

Patients on dialysis report an average of 9-12 symptoms at any given time $e^{92,93,107}$. To determine which of these should be prioritized for intervention, the Kidney Health Initiative used a two-step patient-focused process involving focus groups and an online survey to identify six symptoms that should be prioritized by the research community for intervention. These include three physical symptoms (fatigue, insomnia and cramps) and three mood symptoms (depression, anxiety and frustration) $)^{111}$. Parallel to these efforts, the Standardizing Outcomes in Nephrology Group (SONG) workgroup for haemodialysis (SONG-HD) has identified several tiers of outcomes that are important to patients, caregivers and health-care providers. Fatigue was identified as one of the four core outcomes, whereas depression, pain and feeling washed out after haemodialysis were identified as middle-tier outcomes $^{112-114}$. Along these same lines, the SONG workgroup for PD (SONG-PD) identified the symptoms of fatigue, $\mathrm{PD}$ pain and sleep as important middle-tier outcomes ${ }^{115,116}$. Despite the importance of these symptoms to patients on dialysis, only a few studies have assessed the efficacy of behavioural and pharmacological treatments on depression ${ }^{117-121}$. Even more sobering is the observation that very few, if any, published studies have rigorously tested interventions for fatigue or any of the other symptoms. The nephrology community must now develop standardized and psychometrically robust measures that accurately capture symptoms and outcomes that are important to patients and ensure that these are captured in future clinical trials ${ }^{122,123}$.

Approaches to maximizing functional and social rehabilitation are also important to patients with kidney failure. In addition to the above-mentioned symptoms, SONG-HD identified ability to travel, ability to work, dialysis-free time, impact of dialysis on family and/or friends and mobility as important middle-tier outcomes $^{112-114}$. SONG-PD identified life participation as one of five core outcomes, and impact on family and/or friends and mobility as other outcomes that are important to patients ${ }^{115,116}$. Given the importance of these outcomes to stakeholders, including patients, it is imperative that nephrology researchers develop tools to enable valid and consistent measurement of these outcomes and identify interventions that favourably modify these outcomes.

\section{Fostering innovation}

As described above, the status quo of dialysis care is suboptimal. Residual symptom burden, morbidity and mortality, and economic cost are all unacceptable, which begs the question of what steps are needed to change the established patterns of care. Patients are currently unable to live full and productive lives owing to the emotional and physical toll of dialysis, its intermittent treatment schedule, the dietary and fluid limitations, and their highly restricted mobility during treatment. Current technology requires most patients to travel to a dialysis centre, and current modalities are non-physiological, resulting in 'washout', which is defined as extensive fatigue, nausea and other adverse effects, caused by the build-up of uraemic toxins between treatments and the rapid removal of these solutes and fluids over 4-h sessions in the context of haemodialysis. LMICs face additional difficulties in the provision of dialysis owing to infrastructural requirements, the high cost of this treatment, the need for a constant power supply and the requirement for high volumes of purified water. For LMICs, innovations that focus on home-based, low-cost therapies that promote rehabilitation would be especially beneficial.

We contend that initiatives to transform dialysis outcomes for patients require both top-down efforts (for example, those that involve systems changes at the policy, regulatory, macroeconomic and organizational levels) and bottom-up efforts (for example, patient-led and patient-centred advocacy and individual teams of innovators). Top-down efforts are required to support, facilitate and de-risk the work of innovators. Conversely, patient-led advocacy is essential for influencing governmental and organizational policy change. Here, by considering how selected programmes are attempting to transform dialysis outcomes through innovation in support of high-value, high-quality care, we describe how top-down and bottom-up efforts can work synergistically to change the existing ecosystem of dialysis care (FIG. 2). The efforts described below are not an exhaustive list; rather, this discussion is intended to provide a representative overview of how the dialysis landscape is changing. Additional articles in this issue describe in more detail some of the bottom-up efforts of innovators to create wearable $^{124}$, portable ${ }^{125}$, more environmentally friendly ${ }^{126}$ and more physiological dialysis systems ${ }^{127,128}$, priorities from the patients' perspective ${ }^{129}$, and the role of regulators in supporting innovation in the dialysis space ${ }^{130}$.

\section{The Kidney Health Initiative}

In 2012, the American Society of Nephrology (ASN) and the FDA established the KHI as an umbrella organization through which the kidney community can work collaboratively to remove barriers to the development of innovative drugs, devices, biologics and food products, in order to improve outcomes for people living with kidney diseases. To advance its mission, KHI has initiated a number of projects composed of multidisciplinary workgroups. A major accomplishment for the KHI was the establishment of a precompetitive environment to promote innovation while ensuring patient safety.

The KHI is the largest consortium in the kidney community, with over 100 member organizations including patient groups, health professional organizations, dialysis organizations, pharmaceutical and device companies, and government agencies. During the first 7 years of its existence, the KHI has launched and in many 


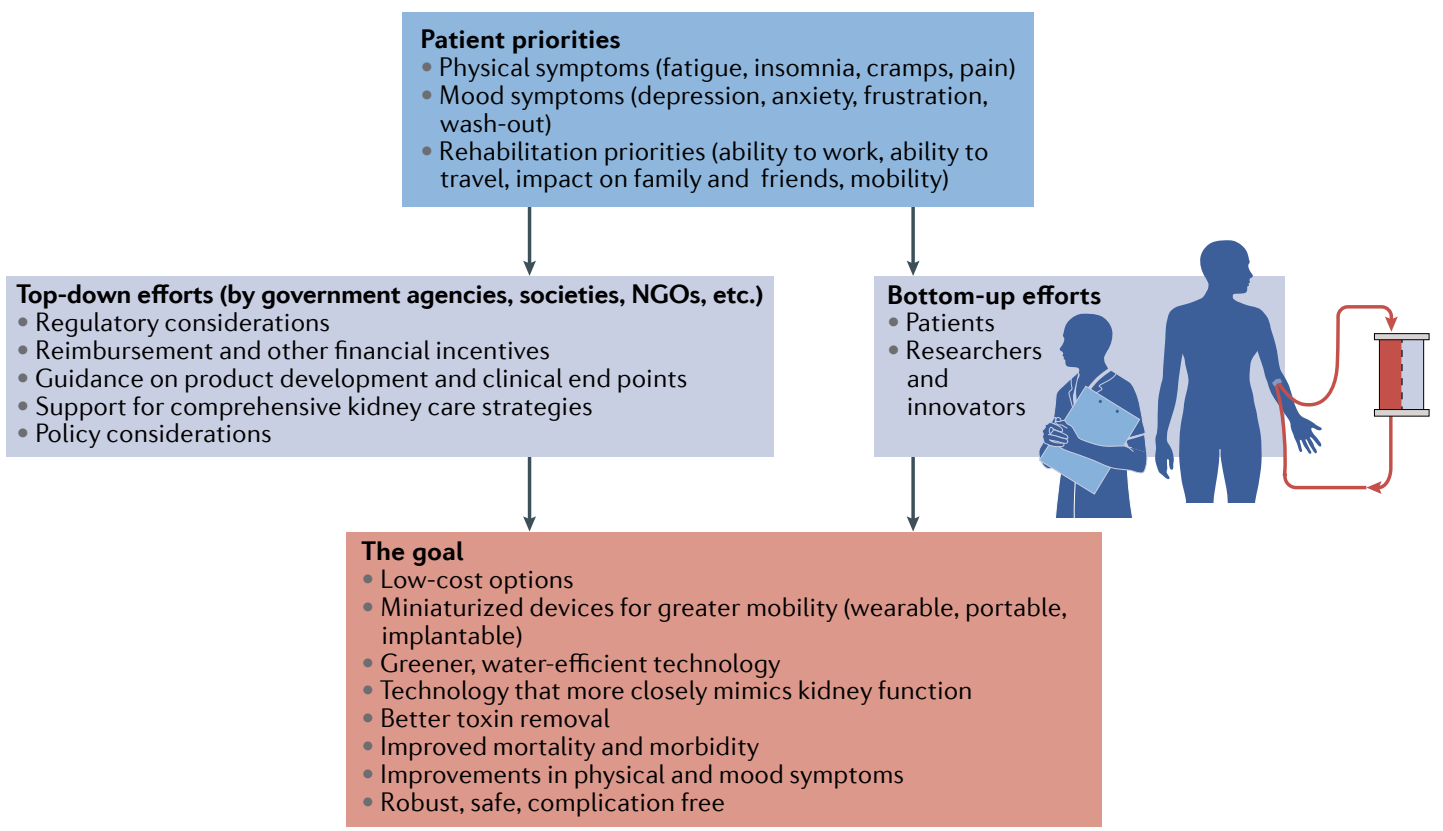

Fig. 2 | Changing the ecosystem of dialysis care and technology to support transformative outcomes. Initiatives to transform dialysis outcomes for patients require both top-down efforts (for example, those that involve systems-level changes at the policy, regulatory, macroeconomic and organizational level) and bottom-up efforts (for example, patientled and patient-centred advocacy efforts and efforts from individual teams of innovators). Both of these efforts need to be guided by priorities identified by patients. Such an approach, focused on patient-centred innovation, has the potential to result in meaningful innovations that support high-quality, high-value care. NGOs, non-governmental organizations.

cases completed projects that have facilitated the development of new therapeutic options for dialysis patients (BOX 2), as well as published position papers on topics relevant to innovation in haemodialysis care, including innovations in fluid management ${ }^{131}$ and symptom management ${ }^{132}$ in patients on haemodialysis, recommendations for clinical trial end points for vascular access $^{133}$, perspectives on pragmatic trials in the haemodialysis population ${ }^{134}$ and regulatory considerations for the use of haemodiafiltration ${ }^{135}$.

\section{Advancing American Kidney Health}

In July 2019, President Donald Trump signed an Executive Order on Advancing American Kidney Health $(\mathrm{AAKH})^{136}$, which promises to fundamentally change the clinical care of kidney disease in general and kidney failure in particular. Components of the AAKH that are relevant to dialysis care include a directive for education and support programmes to promote awareness of kidney disease; a shift in the focus of reimbursement initiatives from in-centre haemodialysis to home therapies, transplantation and upstream CKD care; a system that rewards clinicians and dialysis facilities for providing a range of treatments for kidney failure, with the aim of increasing uptake of home dialysis and transplantation; and incentives for nephrology care teams to focus on reducing costs and improving outcomes by providing longitudinal care of patients with kidney disease.

Finally, and perhaps most radically, the AAKH calls on the US Department of Health and Human Services to support premarket approval of wearable and implantable artificial kidneys and welcomes other strategies to facilitate transformative innovation in dialysis devices.
The AAKH directive specifically identifies the KidneyX programme (described below) as the vehicle with which to drive this innovation. The AAKH is the most ambitious US policy initiative ever undertaken to transform the care of patients with advanced kidney disease. Its agenda is still being shaped by the federal governmental agencies, with input from professional societies and other kidney community stakeholders, but this initiative provides a framework and support for transformative innovation in dialysis care.

\section{The KHI Technology Roadmap and KidneyX}

The KHI Technology Roadmap for Innovative Approaches to KRT, published in 2019 (REF. ${ }^{137}$ ), is aimed at supporting the development of innovative dialysis devices by providing guidance on technical criteria, patient preferences, assessment of patient risk tolerances and regulatory, reimbursement and marketing considerations. Key strengths of the Roadmap include its patient-centred focus and the description of multiple solution pathways for different technologies (for example, portable, wearable and implantable devices that may be purely mechanical, cell-based or hybrid systems), each with appropriate timeline projections.

The KRT Roadmap was designed to be complementary to the Kidney Innovation Accelerator (also known as KidneyX). KidneyX is a public-private partnership between the Department of Health and Human Services and the ASN, and is aimed at accelerating the development of drugs, devices, biologics and other therapies across the spectrum of kidney care. The current major focus of KidneyX is to catalyse the fundamental redesign of dialysis, supported by a series of competitions. Phase I 
Human factors engineers Engineers who design systems, devices, software and tools to fit human capabilities and limitations. prizes focused on innovations in biomaterials, novel biosensors and safety monitors used for haemodialysis, as well as approaches for improved vascular access and the development of novel technologies that replicate kidney function more precisely than conventional dialysis. Phase II focuses on strategies to build and test prototype solutions or components of solutions that can replicate normal kidney function or improve haemodialysis access. KidneyX has also awarded a series of Patient Innovator Challenge prizes to patients who have proposed innovative solutions to problems emanating from their everyday experiences with kidney disease, including approaches to monitoring blood electrolyte levels and increasing the accessibility of patient education resources.

\section{Dutch Kidney Foundation and Neokidney}

The Dutch Kidney Foundation (DKF; or Nierstichting Nederland) was founded in 1968. It supports research into the causes, prevention and treatment of kidney failure. Furthermore, it works to improve the quality of dialysis treatment and increase the number of kidney transplants. All projects are planned and organized with considerable patient involvement. The DKF also offers financial support to kidney research projects by large Dutch multi-centric consortia. These projects not only promote innovation in the Netherlands but also support trans-national European Union (EU)-supported projects with Dutch participation or leadership, such as Horizon 2020 and Horizon Europe.

Neokidney is a partnership between the DKF and several companies that specialize in miniaturization of dialysis equipment (including dialysis pumps) and

\section{Box 2 | Kidney Heath Initiative Projects that Support Dialysis Innovation}

\section{Patient and Family Partnership Council}

Since 2015, the Kidney Health Initiative (KHI) Patient and Family Partnership Council (PFPC) has helped KHI stakeholders to engage and network with patients and patient organizations. The PFPC also advises industry and research partners of patient needs and preferences as new products are planned and developed. The PFPC continually emphasizes that innovation will only be successful if built around the needs of people with kidney disease and focused on improving their quality of life.

\section{ESRD Data Standard Project}

The aim of this project is to create a harmonized common data standard for kidney failure. The availability of a uniform data standard could accelerate the pace of scientific discovery, facilitate the creation of scientific registries for epidemiological surveillance and allow the development of common metrics for value-based health care.

Building Capacity to Incorporate Patient Preferences into the Development of Innovative Alternatives to kidney replacement therapy (KRT) This project, which is supported by a 3-year contract with the FDA, is based on the premise that access to scientifically valid patient preference information could positively inform the decisions of industry and regulators as they design and review new devices for individuals with kidney failure. This project will collect patients' preference information and also address a stated goal of the Advancing American Kidney Health (AAKH) initiative, which instructs the FDA to "develop a new survey to gain insight into patient preferences for new kidney failure treatments" ${ }^{137}$.

Clinical Trial Design to Support Innovative Approaches to KRT

This project is intended to facilitate coordinated efforts between regulators and the nephrology community to streamline the clinical development pathway. The primary objectives of the project are to define terminology for future KRT products (for example, wearable, portable, implantable and artificial kidney) and identify the most appropriate trial designs and end points for a variety of KRT products. sorbent technology for dialysate regeneration. This partnership is aimed at developing a small, portable haemodialysis device that will enable more frequent dialysis sessions, permit more flexibility for patients and improve patient quality of life, as well as reduce health-care costs. The first prototype is currently undergoing preclinical testing and is expected to be tested in humans soon, with the aim of demonstrating proof-of-concept for the first portable haemodialysis machine for daily use, requiring only a limited volume of dialysate. In addition to the development of miniaturization technologies, the partnership is also investigating the use of polymer membranes that permit combined filtration and absorption to achieve more effective haemodialysis ${ }^{138}$.

\section{Nephrologists Transforming Hemodialysis Safety}

Nephrologists Transforming Hemodialysis Safety (NTDS) is a collaborative initiative of the ASN and Centers for Disease Control and Prevention (CDC) that is aimed at addressing a specific complication inherent to contemporary dialysis - infection. In 2016, the CDC observed that $10 \%$ of dialysis patients in the USA died each year as the result of infections - most of which were preventable. The aim of NTDS is to develop and deploy innovations to achieve zero preventable infections in dialysis facilities across the USA. To reach this goal, NTDS uses a multi-pronged approach. For example, education strategies via publication s $^{139-143}$ and webinars that address various aspects of infection prevention and standards of care, use of social media, development of an interactive chapter for trainees and clinicians, and invited lectures are aimed at ensuring that nephrologists, nurses, dialysis administrators and other professionals understand the risk of dialysis-related infections and evidence-based best working practices.

NTDS also interacts with experts in infection detection, prevention and treatment within federal, state and local health departments who can provide advice and assistance that is independent of the regulatory and potentially punitive arms of health departments. NTDS promotes the appropriate use of these experts in settings where expert advice is needed.

To promote leadership among physicians and nurses, NTDS is sponsoring a leadership academy to ensure that knowledge pertaining to evidence-based best working practices is applied to improve workflows in clinical practice. Effective leadership is a requirement, particularly in complex settings, to ensure that patient safety is prioritized and to motivate staff to use best practices.

NTDS are also collaborating with human factors engineers to study the workflows used in haemodialysis facilities and help to define ways of avoiding errors that lead to infection. As a first step in this process, NTDS and human factors engineers have spent time in various haemodialysis facilities to obtain information about the complex processes of care within those facilities, particularly with regard to the use of haemodialysis catheters and approaches to hand hygiene, injection safety and disinfection. Better understanding of current processes may lead to better workflow design.

Finally, based on lessons learned during the Ebola Crisis of 2014, an NTDS work group has designed 
Asynchronous messaging A communication method where the message is placed in a queue, and can be processed at a later time point. processes to anticipate and respond to unexpected health-care crises. At the time of writing this Review, the NTDS team is working with CDC and haemodialysis organizations to anticipate and respond to the COVID-19 epidemic and its effect on dialysis care.

The Affordable Dialysis Prize. As discussed earlier, kidney failure remains a death sentence for many residents of LMICs owing to a lack of access to dialysis. In response to the pressing need for cost-effective dialysis options, the International Society of Nephrology in collaboration with the George Institute for Global Health and the Asian Pacific Society of Nephrology launched the Affordable Dialysis Prize in 2017 with the objective of facilitating the design of a dialysis system that would cost less than US $\$ 1,000$, and provide treatment for less than $\$ 5$ a day, yet be as safe and effective as existing dialysis systems. The prize was awarded to an engineer for a system that runs off solar power and includes a miniature distiller for producing pure water from any source via steam distillation. The purified water can then be mixed with electrolytes in empty PD bags to produce cheap, homemade dialysis solutions. This strategy identifies the lack of cheap, high-quality water as a major impediment to dialysis in LMICs and LICs. The system will ideally fit into a small suitcase ${ }^{144}$. This device remains under development with the goal of initiating clinical trials and ultimately commercializing the technology.

Empowered in-centre haemodialysis. For some patients with kidney failure, maintenance in-centre haemodialysis will always be the preferred treatment, and despite incentivizing policy levers, they will not be interested in pursuing home dialysis or kidney transplantation. In-centre self-dialysis (also referred to as empowered haemodialysis) originated in Sweden, when a young engineer named Christian Farman returned to haemodialysis in 2010 after a failed transplant. Farman began negotiating with his nurses to perform his own dialysis treatments with staff supervision and caught the attention of other patients ${ }^{145}$. Eventually, the process of self-dialysis within this centre - whereby coaches in the dialysis unit train people to take over control of their own treatments and health - grew so popular that a new unit was built at the hospital for self-dialysis patients only, with patient input into the design of the unit. Since then, self-care units were installed in several haemodialysis units in Europe and the USA, offering patients the autonomy and flexibility of home haemodialysis within the safety of a controlled environment. This approach to empowering patients has not been widely used to date, but deserves rigorous study and evaluation ${ }^{146}$.

\section{Remote monitoring to support self-care}

Telemedicine is defined as the electronic exchange of medical information between sites with the aim of improving a patient's health. Telehealth encompasses a broader set of services such as the provision of educational content. New technologies have broadened the scope of telemedicine and telehealth applications and services, making these tools more accessible and useful in the care of patients who live remotely or have difficulty visiting a clinic. The range of services that can be delivered by telehealth now includes two-way interactive video, device data programming, asynchronous messaging, sensors for remote monitoring and portals to enable patients to access electronic health records. Although relatively understudied in haemodialysis patients to date, telehealth has the potential to increase the acceptance of home dialysis and improve patient satisfaction, while potentially decreasing costs and improving outcomes.

Telehealth and the remote monitoring of dialysis patients has become more commonplace in the past decade, particularly in Australia, where telehealth is used widely for patients receiving home dialysis. Telemedicine is also considered a support tool for kidney care in disaster situations such as earthquakes where many individuals in remote locations can be affected. Telemedicine has also been used for distance monitoring of patients receiving $\mathrm{PD}^{147,148}$. In the USA, the Bipartisan Budget Act of 2018 included provisions to expand telehealth coverage to include patients on home dialysis. This legislation allows patients on home dialysis to choose to have their monthly care-provider visits take place via telehealth, without geographic restrictions. The ongoing COVID19 pandemic has also resulted in an unprecedented and rapid expansion in the use of telemedicine for providing health care in many regions worldwide, including for the care of patients undergoing in-centre haemodialysis. The experience gained during this pandemic has the potential to permanently embed telemedicine in health-care delivery in many health-care systems.

Although telehealth has considerable promise for the care of dialysis patients, the implementation of telehealth in clinical practice can be challenging ${ }^{149}$. Telehealth-guided digital interactions have the potential to improve outcomes through the provision of activities such as individualized patient-centred education, remote communication and data exchange, in-home clinical guidance and monitoring, assessment of prescription and/or treatment efficacy and adherence, real-time modification of treatments and early alerts for problems that require intervention, although all of these interventions need to be rigorously tested ${ }^{150}$.

\section{The European Kidney Health Alliance}

The European Kidney Health Alliance (EKHA) is a non-governmental organization based in Brussels, Belgium, which advocates for kidney patients and the nephrology community at relevant bodies of the EU and also at European national organizations. The EKHA represents all of the major stakeholders in kidney care, including physicians, patients, nurses and foundations. The actions of the EKHA are supported by a dedicated group of Members of European Parliament. Of note, according to the treaty of Lisbon ${ }^{151}$, health-care systems are the responsibility of the national authorities of EU countries, which limits the role of the European Commission to one of complementing national policies and fostering cooperation. The EKHA has undertaken several initiatives in the area of kidney care, mainly focusing on measures to decrease the costs of kidney care while maintaining quality of care and access for 
all appropriate candidates, and to reduce demand for dialysis by promoting efforts to prevent the progression of kidney disease, and encouraging kidney transplantation as the KRT of choice ${ }^{66,152}$. In 2021, the EKHA will focus on reimbursement strategies and access to KRT, especially home haemodialysis.

The Nephrology and Public Policy Committee is a similar initiative created by the European Renal AssociationEuropean Dialysis and Transplant Association (ERA-EDTA). This committee aims to translate important kidney-related clinical topics into public policy, including the search for novel biomarkers of CKD, improving transition between paediatric and adult nephrology, and improving collaboration between the ERA-EDTA Registry and the guidance body of the ERA-EDTA, European Renal Best Practice $^{153}$.

\section{Beating Kidney Disease}

Together with the Dutch Federation for Nephrology and the Dutch Kidney Patients Association, the DKF has initiated a strategic agenda for research and innovation in the Netherlands. This initiative, called Beating Kidney Disease (Nierziekte de Baas) will promote four specific research areas ${ }^{154}$ : prevention of kidney failure, including root causes such as other chronic diseases; personalized medicine including genome and big data analyses, and studies of rare diseases; patient-centred outcomes and quality of life, transplantation and home haemodialysis; and regenerative medicine including bio-artificial kidneys. In collaboration with the EKHA, the Beating Kidney Disease initiative will be proposed as a framework for future initiatives at the Directorate
General for Health and Food Safety of the European Commission, and the European Commissioner of Health. Similar to European initiatives that have promoted transplantation ${ }^{152,155,156}$, these efforts will emphasize shifts in policy action to strengthen institutional frameworks, improve education, training and information, optimize registries, and ensure appropriate benchmarking in nephrology.

\section{Conclusions}

The past 50 years have seen rapid changes in how and to whom dialysis is provided. From a global perspective, the escalating numbers of patients who require dialysis mean that even current costs are not sustainable, and yet most people who develop kidney failure forego treatment owing to a lack of access, with millions of lives lost every year as a consequence. Also important, the limitations of current dialysis treatment in alleviating patient suffering, morbidity and mortality are now viewed as unacceptable. Consequently, patients, payors, regulators and health-care systems are increasingly demanding improved value, which can only come about through true patient-centred innovation that supports high-quality, high-value care. Substantial efforts are now underway to support requisite transformative changes. These efforts need to be catalysed, promoted and fostered through international collaboration and harmonization to ensure that in the future, people living with kidney failure have more and better treatment options than exist today.

Published online 30 July 2020
1. Peitzman, S. J. Chronic dialysis and dialysis doctors in the United States: a nephrologist-historian's perspective. Semin. Dial. 14, 200-208 (2001)

2. Brescia, M. J., Cimino, J. E., Appel, K. \& Hurwich, B. J. Chronic hemodialysis using venipuncture and a surgically created arteriovenous fistula. N. Engl. J. Med. 275, 1089-1092 (1966)

3. Blagg, C. R. The early history of dialysis for chronic renal failure in the United States: a view from Seattle. Am. J. Kidney Dis. 49, 482-496 (2007).

4. Scribner, B. H. Ethical problems of using artificial organs to sustain human life. Trans. Am. Soc. Artif Intern. Organs 10, 209-212 (1964).

5. Blagg, D. C. R. From Miracle to Mainstream: Creating the World's First Dialysis Organization (Northwest Kidney Centers, 2017)

6. Himmelfarb, J., Berns, A., Szczech, L. \& Wesson, D. Cost, quality, and value: the changing political economy of dialysis care. J. Am. Soc. Nephrol. 18 , 2021-2027 (2007)

7. KDIGO. KDIGO 2012 clinical practice guideline for the evaluation and management of chronic kidney disease. Kidney Int. Suppl. 3, 163 (2013).

8. Hole, B. et al. Supportive care for end-stage kidney disease: an integral part of kidney services across a range of income settings around the world. Kidney Int Suppl. 10, e86-e94 (2020).

9. Bikbov, B. et al. Global, regional, and national burden of chronic kidney disease, 1990-2017: a systematic analysis for the Global Burden of Disease Study 2017. Lancet 395, 709-733 (2020).

10. Liyanage, T. et al. Worldwide access to treatment for end-stage kidney disease: a systematic review. Lancet 385, 1975-1982 (2015).

11. Tonelli, M. et al. Framework for establishing integrated kidney care programs in low- and middleincome countries. Kidney Int. Suppl. 10, e19-e23 (2020).

12. Pecoits-Filho, R. et al. Capturing and monitoring global differences in untreated and treated end-stage kidney disease, kidney replacement therapy modality, and outcomes. Kidney Int. Suppl. 10, e3-e9 (2020).
13. Bello A. K. L. et al. Global Kidney Health Atlas: a report by the International Society of Nephrology on the current state of organization and structures for kidney care across the globe. https://www. kidneycareuk.org/documents/52/ISN_Global_kidney_ health_atlas.pdf (2017).

14. White, S. et al. How can we achieve global equity in provision of renal replacement therapy? Bull. World Health Organ. 86, 229-237 (2008).

15. Bello, A. K. et al. Status of care for end stage kidney disease in countries and regions worldwide: international cross sectional survey. BMJ 367, 15873 (2019).

16. Luxardo, R. et al. The epidemiology of renal replacement therapy in two different parts of the world: the Latin American Dialysis and Transplant Registry versus the European Renal AssociationEuropean Dialysis and Transplant Association Registry. Rev. Panam. Salud Publica 42, e87 (2018)

17. United States Renal Data System. Volume 2: ESRD in the United States https://www.usrds.org/2018/ download/2018_Volume_2_ESRD_in_the_US.pdf (2018).

18. Jha, V. et al. The state of nephrology in South Asia. Kidney Int. 95, 31-37 (2019).

19. Barsoum, R. S., Khalil, S. S. \& Arogundade, F. A. Fifty years of dialysis in Africa: challenges and progress. Am. J. Kidney Dis. 65, 502-512 (2015).

20. Bello, A. K. et al. Assessment of Global Kidney Health Care Status. JAMA 317, 1864-1881 (2017)

21. Fresenius Medical Care. Annual Report 2018: Care and Live. https://www.freseniusmedicalcare.com/ fileadmin/data/com/pdf/Media_Center/Publications/ Annual_Reports/FME_Annual-Report_2018.pdf (2018).

22. United States Renal Data System. US Renal Data System 2019 Annual Data Report: epidemiology of kidney disease in the United States. https://www.usrds. org/2019/view/USRDS_2019_ES_final.pdf (2019).

23. Liu, F. X. et al. A global overview of the impact of peritoneal dialysis first or favored policies: an opinion. Perit. Dial. Int. 35, 406-420 (2015).
24. Mehrotra, R. et al. Racial and ethnic disparities in use of and outcomes with home dialysis in the United States. J. Am. Soc. Nephrol. 27, 2123-2134 (2016).

25. Li, P. K.-T. et al. Changes in the worldwide epidemiology of peritoneal dialysis. Nat. Rev. Nephrol. 13, 90-103 (2017).

26. ANZDATA Registry. ANZDATA 42nd Annual Report 2019. https://www.anzdata.org.au/report/anzdata42nd-annual-report-2019/ (2019).

27. Kramer, A. et al. The European Renal Association European Dialysis and Transplant Association (ERA-EDTA) Registry annual report 2015: a summary. Clin. Kidney J. 11, 108-122 (2018).

28. Anand, S., Bitton, A. \& Gaziano, T. The gap between estimated incidence of end-stage renal disease and use of therapy. PLOS ONE 8, e72860 (2013).

29. Modi, G. K. \& Jha, V. The incidence of end-stage renal disease in India: a population-based study. Kidney Int 70, 2131-2133 (2006).

30. Robinson, B. M. et al. Factors affecting outcomes in patients reaching end-stage kidney disease worldwide: differences in access to renal replacement therapy, modality use, and haemodialysis practices. Lancet 388, 294-306 (2016)

31. Antlanger, M. et al. Sex differences in kidney replacement therapy initiation and maintenance. Clin. J. Am. Soc. Nephrol. 14, 1616 (2019).

32. Chan, K. E. et al. Early outcomes among those initiating chronic dialysis in the United States. Clin. J. Am. Soc. Nephro 6, 2642-2649 (2011).

33. Thamer, M. et al. Predicting early death among elderly dialysis patients: development and validation of a risk score to assist shared decision making for dialysis initiation. Am. J. Kidney Dis. 66, 1024-1032 (2015).

34. Garcia-Garcia, G. et al. Survival among patients with kidney failure in Jalisco, Mexico. J. Am. Soc. Nephrol. 18, 1922-1927 (2007).

35. Foster, B. J., Mitsnefes, M. M., Dahhou, M., Zhang, X $\&$ Laskin, B. L. Changes in excess mortality from end stage renal disease in the United States from 1995 to 2013. Clin. J. Am. Soc. Nephrol. 13, 91-99 (2018). 
36. Storey, B. C. et al. Declining comorbidity-adjusted mortality rates in English patients receiving maintenance renal replacement therapy. Kidney Int. 93, 1165-1174 (2018)

37. Fenton, S. S. et al. Hemodialysis versus peritoneal dialysis: a comparison of adjusted mortality rates. Am. J. Kidney Dis. 30, 334-342 (1997).

38. Vonesh, E. F., Snyder, J. J., Foley, R. N. \& Collins, A. J. The differential impact of risk factors on mortality in hemodialysis and peritoneal dialysis. Kidney Int. 66 2389-2401 (2004).

39. Mehrotra, R., Chiu, Y. W., Kalantar-Zadeh, K, Bargman, J. \& Vonesh, E. Similar outcomes with hemodialysis and peritoneal dialysis in patients with end-stage renal disease. Arch. Intern. Med. 171, 110-118 (2011).

40. Mehrotra, R., Devuyst, O., Davies, S. J. \& Johnson, D. W. The current state of peritoneal dialysis. J. Am. Soc. Nephrol. 27, 3238-3252 (2016).

41. Mehrotra, R. et al. Chronic peritoneal dialysis in the United States: declining utilization despite improving outcomes. J. Am. Soc. Nephrol. 18, 2781-2788 (2007).

42. Modi, Z. J. et al. Risk of cardiovascular disease and mortality in young adults with end-stage renal disease: an analysis of the us renal data system. JAMA Cardiol. 4, 353-362 (2019).

43. Wetmore, J. B. et al. Insights from the 2016 peer kidney care initiative report: still a ways to go to improve care for dialysis patients. Am. J. Kidney Dis. 71, 123-132 (2018)

44. Skov Dalgaard, L. et al. Risk and prognosis of bloodstream infections among patients on chronic hemodialysis: a population-based cohort study. PLoS One 10, e0124547 (2015)

45. Nelveg-Kristensen, K. E., Laier, G. H. \& Heaf, J. G. Risk of death after first-time blood stream infection in incident dialysis patients with specific consideration on vascular access and comorbidity. BMC Infect. Dis. 18, 688 (2018).

46. Chaudry, M. S. et al. Risk of infective endocarditis in patients with end stage renal disease. Clin. J. Am. Soc Nephrol. 12, 1814-1822 (2017).

47. Pruthi, R., Steenkamp, R. \& Feest, T. UK renal registry 16 th annual report: chapter 8 survival and cause of death of UK adult patients on renal replacement therapy in 2012: national and centre-specific analyses. Nephron. Clin. Pract. 125, 139-169 (2013).

48. Kucirka, L. M. et al. Association of race and age with survival among patients undergoing dialysis. JAMA 306, 620-626 (2011)

49. van den Beukel, T. O. et al. The role of psychosocial factors in ethnic differences in survival on dialysis in The Netherlands. Nephrol. Dial. Transpl. 27, 2472-2479 (2012)

50. Depner, T. et al. Dialysis dose and the effect of gender and body size on outcome in the HEMO study. Kidney Ing. 65, 1386-1394 (2004).

51. Villar, E., Remontet, L., Labeeuw, M. \& Ecochard, R. Effect of age, gender, and diabetes on excess death in end-stage renal failure. J. Am. Soc. Nephrol. 18, 2125-2134 (2007).

52. Hecking, M. et al. Sex-specific differences in hemodialysis prevalence and practices and the male to-female mortality rate: the dialysis outcomes and practice patterns study (DOPPS). PLoS Med. 11 , e1001750 (2014)

53. Erickson, K. F., Zhao, B., Ho, V. \& Winkelmayer, W. C. Employment among patients starting dialysis in the United States. Clin. J. Am. Soc. Nephrol. 13, 265-273 (2018)

54. Kurella Tamura, M. et al. Functional status of elderly adults before and after initiation of dialysis. N. Eng. J. Med. 361, 1539-1547 (2009).

55. Daratha, K. B. et al. Risks of subsequent hospitalization and death in patients with kidney disease. Clin. J. Am. Soc. Nephrol. 7, 409-416 (2012).

56. Davison, S. N. \& Jhangri, G. S. Impact of pain and symptom burden on the health-related quality of life of hemodialysis patients. J. Pain. Symptom Manage. 39 477-485 (2010)

57. Eneanya, N. D. et al. Longitudinal patterns of healthrelated quality of life and dialysis modality: a national cohort study. BMC Nephrol. 20, 7 (2019).

58. Ju, A. et al. Patient-reported outcome measures for fatigue in patients on hemodialysis: a systematic review. Am. J. Kidney Dis. 71, 327-343 (2018).

59. Rhee, E. P. et al. Prevalence and persistence of uremic symptoms in incident dialysis patients. Kidney360 1, 86-92 (2020)

60. Kimmel, P. L. \& Peterson, R. A. Depression in patients with end-stage renal disease treated with dialysis: has the time to treat arrived? Clin. J. Am. Soc. Nephrol. 1, 349-352 (2006)

61. Burnier, M., Pruijm, M., Wuerzner, G. \& Santschi, V. Drug adherence in chronic kidney diseases and dialysis. Nephrol. Dial. Transpl. 30, 39-44 (2015).

62. Viecelli, A. K. et al. Identifying critically important vascular access outcomes for trials in haemodialysis: an international survey with patients, caregivers and health professionals. Nephrol. Dial. Transpl. 35 657-668 (2020)

63. Ceretta, M. L. et al. Changes in co-morbidity pattern in patients starting renal replacement therapy in Europe-data from the ERA-EDTA registry. Nephrol. Dial. Transpl. 33, 1794-1804 (2018).

64. Vanholder, R. et al. Reimbursement of dialysis: a comparison of seven countries. J. Am. Soc. Nephrol. 23, 1291-1298 (2012)

65. Winkelmayer, W. C., Weinstein, M. C., Mittleman, M. A Glynn, R. J. \& Pliskin, J. S. Health economic evaluations: the special case of end-stage renal disease treatment. Med. Decis. Mak. 22, 417-430 (2002).

66. Vanholder, R. et al. Reducing the costs of chronic kidney disease while delivering quality health care: a call to action. Nat. Rev. Nephrol. 13, 393-409 (2017).

67. Klarenbach, S. \& Manns, B. Economic evaluation of dialysis therapies. Semin. Nephrol. 29, 524-532 (2009).

68. van der Tol, A., Lameire, N., Morton, R. L., Van Biesen, W. \& Vanholder, R. An internationa analysis of dialysis services reimbursement. Clin $\mathrm{J}$. Am. Soc. Nephrol. 14, 84-93 (2019).

69. Beaudry, A. et al. Cost of dialysis therapy by modality in Manitoba. Clin. J. Am. Soc. Nephrol. 13 1197-1203 (2018)

70. Golper, T. A. The possible impact of the US prospective payment system ("bundle") on the growth of peritoneal dialysis. Perit. Dial. Int. 33, 596-599 (2013).

71. Lin, E. et al. Home dialysis in the prospective paymen system era. J. Am. Soc. Nephrol. 28, 2993-3004 (2017).

72. Shen, J. I. et al. Expanded prospective paymen system and use of and outcomes with home dialysis by race and ethnicity in the United States. Clin. J. Am Soc. Nephrol. 14, 1200-1212 (2019).

73. Wang, V. et al. Medicare's new prospective payment system on facility provision of peritoneal dialysis. Clin. J. Am. Soc. Nephrol. 13, 1833-1841 (2018).

74. Swanepoel, C. R., Wearne, N. \& Okpechi, I. G. Nephrology in Africa-not yet uhuru. Nat. Rev. Nephrol. 9, 610-622 (2013).

75. Wang V Vilme, $\mathrm{H}$, Maciejewski, M L $\mathrm{\alpha}$ Boulware, L. E. The economic burden of chronic kidne disease and end-stage renal disease. Semin. Nephrol. 36, 319-330 (2016)

76. Martin, D. E. et al. A call for professional collaboration to address ethical challenges in nephrology. Nat Rev Nephrol. https://doi.org/10.1038/s41581-020-0295-4 (2020).

77. Harris, D. C. H. et al. Increasing access to integrated ESKD care as part of universal health coverage. Kidney Int 95, S1-S33 (2019).

78. Rodriguez, R. A. Dialysis for undocumented immigrants in the United States. Adv. Chronic Kidney Dis. 22, 60-65 (2015).

79. Saunders, M. R., Lee, H., Maene, C., Schuble, T. $\&$ Cagney, K. A. Proximity does not equal access: racial disparities in access to high quality dialysis facilities. J. Racial Ethn. Health Disparities 1, 291-299 (2014)

80. Shaikh, M. et al. Utilization, costs, and outcomes for patients receiving publicly funded hemodialysis in India. Kidney Int 94, 440-445 (2018).

81. Ladin, K. \& Smith, A. K. Active medical management for patients with advanced kidney disease. JAMA Intern. Med. 179, 313-315 (2019).

82. Boulware, L. E., Wang, V. \& Powe, N. R. Improving access to kidney transplantation: business as usual or new ways of doing business? JAMA 322, 931-933 (2019).

83. Van Biesen, W., van der Veer, S. N., Murphey, M., Loblova, O. \& Davies, S. Patients' perceptions of information and education for renal replacement therapy: an independent survey by the European Kidney Patients' Federation on information and support on renal replacement therapy. PLOS ONE 9 e103914 (2014)

84. Mehrotra, R., Marsh, D., Vonesh, E., Peters, V. \& Nissenson, A. Patient education and access of ESRD patients to renal replacement therapies beyond in-center hemodialysis. Kidney Int. 68, 378-390 (2005)
85. Taylor, D. M. et al. A systematic review of the prevalence and associations of limited health literacy in CKD. Clin. J. Am. Soc. Nephrol. 12, 1070-1084 (2017).

86. Vanholder, R., Van Biesen, W. \& Lameire, N. Renal replacement therapy: how can we contain the costs? Lancet 383, 1783-1785 (2014).

87. Moss, A. H. Revised dialysis clinical practice guideline promotes more informed decision-making. Clin. J. Am. Soc. Nephrol. 5, 2380-2383 (2010)

88. Williams, A. W. et al. Critical and honest conversations: the evidence behind the "Choosing Wisely" campaign recommendations by the American Society of Nephrology. Clin. J. Am. Soc. Nephrol. 7, 1664-1672 (2012).

89. Rinehart, A. Beyond the futility argument: the fair process approach and time-limited trials for managing dialysis conflict. Clin. J. Am. Soc. Nephrol. 8 2000-2006 (2013).

90. Ladin, K. et al. Characterizing approaches to dialysis decision making with older adults: a qualitative study of nephrologists. Clin. J. Am. Soc. Nephrol. 13, 1188-1196 (2018).

91. Luyckx, V. A. et al. Developing the ethical framework of end-stage kidney disease care: from practice to policy. Kidney Int. Suppl. 10, e72-e77 (2020).

92. Davison, S. N., Jhangri, G. S. \& Johnson, J. A. Crosssectional validity of a modified Edmonton symptom assessment system in dialysis patients: a simple assessment of symptom burden. Kidney Int. 69 1621-1625 (2006).

93. Weisbord, S. D. et al. Renal provider recognition of symptoms in patients on maintenance hemodialysis. Clin. J. Am. Soc. Nephrol. 2, 960-967 (2007).

94. Eknoyan, G. et al. Effect of dialysis dose and membrane flux in maintenance hemodialysis. N. Engl. J. Med. 347, 2010-2019 (2002).

95. Paniagua, R. et al. Effects of increased peritoneal clearances on mortality rates in peritoneal dialysis: ADEMEX, a prospective, randomized, controlled trial. J. Am. Soc. Nephrol. 13, 1307-1320 (2002).

96. Locatelli, F. et al. Effect of membrane permeability on survival of hemodialysis patients. J. Am. Soc. Nephrol. 20, 645-654 (2009)

97. Group, F. H. N. T. et al. In-center hemodialysis six times per week versus three times per week. N. Engl. J. Med. 363, 2287-2300 (2010).

98. Rocco, M. V. et al. The effects of frequent nocturnal home hemodialysis: the frequent hemodialysis network nocturnal trial. Kidney Int. 80, 1080-1091 (2011).

99. Grooteman, M. P. C. et al. Effect of online hemodiafiltration on all-cause mortality and cardiovascular outcomes. J. Am. Soc. Nephrol. 23, 1087 (2012).

100. Farrington, K. \& Davenport, A. The ESHOL study: hemodiafiltration improves survival - but how? Kidney Int. 83, 979-981 (2013).

101. Maduell, F. et al. High-efficiency postdilution online hemodiafiltration reduces all-cause mortality in hemodialysis patients. J. Am. Soc. Nephrol. 24 487 (2013)

102. Besarab, A. et al. The effects of normal as compared with low hematocrit values in patients with cardiac disease who are receiving hemodialysis and epoetin N. Engl. J. Med. 339, 584-590 (1998)

103. Suki, W. N. et al. Effects of sevelamer and calciumbased phosphate binders on mortality in hemodialysis patients. Kidney Int 72, 1130-1137 (2007).

104. Wanner, C. et al. Atorvastatin in patients with type 2 diabetes mellitus undergoing hemodialysis. N. Engl. J. Med. 353, 238-248 (2005).

105. Fellstrom, B. C. et al. Rosuvastatin and cardiovascular events in patients undergoing hemodialysis. N. Engl. J. Med. 360, 1395-1407 (2009).

106. Baigent, C. et al. The effects of lowering LDL cholesterol with simvastatin plus ezetimibe in patients with chronic kidney disease (Study of Heart and Renal Protection): a randomised placebo-controlled trial. Lancet 377, 2181-2192 (2011).

107. Abdel-Kader, K., Unruh, M. L. \& Weisbord, S. D. Symptom burden, depression, and quality of life in chronic and end-stage kidney disease. Clin. J. Am. Soc. Nephrol. 4, 1057-1064 (2009).

108. Mehrotra, R., Berman, N., Alistwani, A. \& Kopple, J. D. Improvement of nutritional status after initiation of maintenance hemodialysis. Am. J. Kidney Dis. 40, 133-142 (2002)

109. Pupim, L. B. et al. Improvement in nutritional parameters after initiation of chronic hemodialysis. Am. J. Kidney Dis. 40, 143-151 (2002)

110. Rivara, M. B. et al. Changes in symptom burden and physical performance with initiation of dialysis in 
patients with chronic kidney disease. Hemodial. Int. 19, 147-150 (2015)

111. Flythe, J. E. et al. Symptom prioritization among adults receiving in-center hemodialysis: a mixed methods study. Clin. J. Am. Soc. Nephrol. 13 735-745 (2018).

112. Tong, A. et al. Establishing core outcome domains in hemodialysis: report of the standardized outcomes in nephrology-hemodialysis (SONG-HD) consensus workshop. Am. J. Kidney Dis. 69, 97-107 (2017).

113. Evangelidis, N. et al. Developing a set of core outcomes for trials in hemodialysis: an international Delph survey. Am. J. Kidney Dis. 70, 464-475 (2017)

114. Urquhart-Secord, R. et al. Patient and caregiver priorities for outcomes in hemodialysis: an international nominal group technique study. Am. J. Kidney Dis. 68, 444-454 (2016)

115. Manera, K. E. et al. Patient and caregiver priorities for outcomes in peritoneal dialysis: multinational nominal group technique study. Clin. J. Am. Soc. Nephrol. 14, 74-83 (2019)

116. Manera, K. E. et al. An international Delphi survey helped develop consensus-based core outcome domains for trials in peritoneal dialysis. Kidney Int 96, 699-710 (2019).

117. Duarte, P. S., Miyazaki, M. C., Blay, S. L. \& Sesso, R. Cognitive-behavioral group therapy is an effective treatment for major depression in hemodialysis patients. Kidney Int. 76, 414-421 (2009).

118. Taraz, M. et al. Sertraline decreases serum level of interleukin-6 (IL-6) in hemodialysis patients with depression: results of a randomized double-blind, placebo-controlled clinical trial. Int. Immunopharmacol. 17, 917-923 (2013).

119. Cukor, D. et al. Psychosocial intervention improves depression, quality of life, and fluid adherence in hemodialysis. J. Am. Soc. Nephrol. 25, 196-206 (2014).

120. Friedli, K. et al. Sertraline versus placebo in patients with major depressive disorder undergoing hemodialysis: a randomized, controlled feasibility trial. Clin. J. Am. Soc. Nephrol. 12, 280-286 (2017).

121. Mehrotra, R. et al. Comparative efficacy of therapies for treatment of depression for patients undergoing maintenance hemodialysis: a randomized clinical trial. Ann. Intern. Med. 170, 369-379 (2019).

122. Mendu, M. L. et al. Measuring quality in kidney care: an evaluation of existing quality metrics and approach to facilitating improvements in care delivery. J. Am. Soc. Nephrol. 31, 602-614 (2020).

123. Nair, D. \& Wilson, F. P. Patient-reported outcome measures for adults with kidney disease: current measures, ongoing initiatives, and future opportunities for incorporation into patient-centered kidney care. Am. J. Kidney Dis. 74, 791-802 (2019).

124. Himmelfarb, J. \& Ratner, B. Wearable artificial kidney: problems, progress and prospects. Nat. Rev. Nephrol. in press [doi to be supplied]

125. Foo, M. W. Y. \& Htay, H. Innovations in peritoneal dialysis. Nat. Rev. Nephrol. https://doi.org/10.1038/ s41581-020-0283-8 (2020)

126. Agar, J. W. M. \& Barraclough, K. A. Water use in dialysis: environmental considerations. Nat. Rev. Nephrol. https://doi.org/10.1038/s41581-020-0296-3 (2020).

127. Masereeuw, R. \& Verhaar, M. C. Innovations in approaches to remove uraemic toxins. Nat. Rev. Nephrol. https://doi.org/10.1038/s41581-020-0299-0 (2020).

128. Geremia, I. \& Stamatialis, D. Innovations in dialysis membranes for improved kidney replacement therapy. Nat. Rev. Nephrol. https://doi.org/10.1038/s41581020-0293-6 (2020).

129. Gedney, N., Sipma, W. \& Søndergaard, H. Innovations in dialysis: the user's perspective. Nat. Rev. Nephrol. https://doi.org/10.1038/s41581-020-0292-7 (2020).
130. Wieringa, F. P., Sheldon, M. I. \& Hidalgo-Simon, A. Regulatory approaches to stimulate innovative renal replacement therapies. Nat. Rev. Nephrol. https://doi. org/10.1038/s41581-020-0275-8 (2020).

131. Kidney Health Initiatve. Fostering Innovation in Fluid Management. https://khi.asn-online.org/uploads/KHI InnovationsInFluidManagement.pdf (2019).

132. Flythe, J. E. et al. Fostering innovation in symptom management among hemodialysis patients. Clin. J. Am. Soc. Nephrol. 14, 150 (2019).

133. Shenoy, S. et al. Clinical trial end points for hemodialysis vascular access. Clin. J. Am. Soc. Nephrol. 13, 490 (2018).

134. Dember, L. M. et al. Pragmatic trials in maintenance dialysis: perspectives from the kidney health initiative. J. Am. Soc. Nephrol. 27, 2955 (2016).

135. Canaud, B. Vienken, J., Ash S. \& Ward, R. A. Hemodiafiltration to address unmet medical needs ESKD patients. Clin. J. Am. Soc. Nephrol. 13, 1435 (2018).

136. Trump, D. J. Executive Order on Advancing American Kidney Health. The White House https://www. whitehouse.gov/presidential-actions/executiveorder-advancing-american-kidney-health/ (2019).

137. Kidney Health Initiative. Technology Roadmap for Innovative Approaches to Renal Replacement Therapy. https://www. asn-online.org/g/blast/files/ KHI_RRT_Roadmap 1.0_FINAL_102318_web.pdf (2018).

138. Tijink, M. S. L. et al. Mixed matrix membranes: a new asset for blood purification therapies. Blood Purif. 37 , 1-3 (2014).

139. Vijayan, A. \& Boyce, J. M. $100 \%$ use of infection control procedures in hemodialysis facilities: call to action. Clin. J. Am. Soc. Nephrol. 13, 671-673 (2018).

140. Wong, L. P. Achieving dialysis safety: the critical role of higher-functioning teams. Semin. Dial. 32, 266-273 (2019).

141. Kliger, A. S. \& Collins, A. J. Long overdue need to reduce infections with hemodialysis. Clin. J. Am. Soc. Nephrol. 12, 1728-1729 (2017).

142. Kliger, A. S. Targeting zero infections in dialysis: new devices, yes, but also guidelines, checklists, and a culture of safety. J. Am. Soc. Nephrol. 29, 1083-1084 (2018).

143. Collins, A. J. \& Kliger, A. S. Urgent: stop preventable infections now. Clin. J. Am. Soc. Nephrol. 13 663-665 (2018)

144. The George Institute. World's first affordable dialysis machine a finalist in 2017 Eureka Awards. https:/ www.georgeinstitute.org.au/media-releases/worldsfirst-affordable-dialysis-machine-a-finalist-in-2017eureka-awards (2017).

145. Institute for Healthcare Improvement. A patient directs his own care. http://www.ihi.org/resources/ Pages/ImprovementStories/APatientDirectsHisOwn CareFarmanSelfDialysis.aspx (2020).

146. Shinkman, R. Is "empowered dialysis" the key to bette outcomes? NEJM Catalyst Carryover https://doi.org/ 10.1056/CAT. 18.0232 (2018)

147. Nayak, K. S., Ronco, C., Karopadi, A. N. \& Rosner, M. H. Telemedicine and remote monitoring: supporting the patient on peritoneal dialysis. Perit. Dial. Int. 36 362-366 (2016)

148. Rohatgi, R., Ross, M. J. \& Majoni, S. W. Telenephrology: current perspectives and future directions. Kidney Int. 92, 1328-1333 (2017).

149. Lew, S. Q. \& Sikka, N. Operationalizing telehealth for home dialysis patients in the United States. Am. J. Kidney Dis. 74, 95-100 (2019).

150. Bieber, S. D. \& Gadegbeku, C. A. A call to action for the kidney community: nephrologists' perspective on advancing American kidney health. Clin. J. Am. Soc. Nephrol. 14, 1799-1801 (2019).

151. Foundation for EU democracy. Consolidated Reader Friendly Edition of the Treaty on European Union (TEU) and the Treaty on the Functioning of the European
Union (TFEU) as amended by the Treaty of Lisbon (2007) Third edition. http//en euabc.com/upload/ books/lisbon-treaty-3edition.pdf (2009).

152. European Kidney Health Alliance. Thematic Network on Improving Organ Donation and Transplantation in the EU 2019. http://ekha.eu/wp-content/uploads/ FINAL Joint-Statement-of-the-Thematic-Network-onOrgan-Donation-and-Transplantation.pdf (2019).

153. Massy, Z. A. et al. Nephrology and public policy committee propositions to stimulate research collaboration in adults and children in Europe. Nephrol. Dial. Transpl. 34, 1469-1480 (2019).

154. Beating kidney disease. A joint agenda for research and innovation. https://www.nierstichting.nl/media/ filer_public/4d/6d/4d6d6b4e-ce56-4a4b8ba2-f5ac957d0df8/beating_kidney disease - joint agenda for ri june 2018.pdf (2018).

155. Matesanz, R., Marazuela, R., Coll, E., Mahillo, B. \& Dominguez-Gil, B. About the Opt-Out system, live transplantation, and information to the public on organ donation in Spain... Y ole! Am. J. Transpl. 17 1695-1696 (2017).

156. Zivcic-Cosic, S. et al. Development of the Croatian model of organ donation and transplantation. Croat. Med. J. 54, 65-70 (2013).

\section{Author contributions}

The authors contributed equally to all aspects of the article.

\section{Competing interests}

J.H. declares that The Kidney Research Institute and the Center for Dialysis Innovation at the University of Washington, which he directs, has received gift and grant support from the Northwest Kidney Centers, a not-for-profit dialysis provider. The Center for Dialysis Innovation has also received a Phase I prize from KidneyX, and a grant from the Veterans Administration. J.H. is also a founder and holds equity in AKTIV-X Technologies, Inc. R.V. has consulted for Baxter Healthcare, B. Braun and Neokidney. R.M. has received an honorarium from Baxter Healthcare and serves as a member of the Board of Trustees of the Northwest Kidney Centers. M.T. has received a lecture fee from B. Braun, which was donated to charity.

\section{Peer review information}

Nature Reviews Nephrology thanks M. Verhaar, who co-reviewed with M. van Gelder, and the other, anonymous, reviewer(s) for their contribution to the peer review of this work.

\section{Publisher's note}

Springer Nature remains neutral with regard to jurisdictional claims in published maps and institutional affiliations.

\section{RELATED LINKS}

Affordable Dialysis Prize: https://www.dialysisprize.org/

Dutch Kidney Foundation: https://www.narcis.nl/ organisation/RecordID/ORG1238896/Language/en ESRD Data Standard Project: https://khi.asn-online.org/ projects/project.aspx?ID=78

European Kidney Health Alliance: http://ekha.eu/ Kidney Health Initiative: https://khi.asn-online.org/ KidneyX: https://www.kidneyx.org/

Neokidney: https://www.nextkidney.com/

Nephrologists Transforming Hemodialysis Safety:

https://www.asn-online.org/ntds/

Nephrology and Public Policy Committee:

https://www.era-edta.org/en/nppc/

Nierstichting Nederland: https://nierstichting.nl/

Patient and Family Partnership Council:

https://khi.asn-online.org/pages/?ID=1

SONG-HD: https://songinitiative.org/projects/song-hd/ SONG-PD: https://songinitiative.org/projects/song-pd/ Standardizing Outcomes in Nephrology Group (SONG): https://songinitiative.org/

(c) Springer Nature Limited 2020 